\title{
Two differentially structured collagen scaffolds for potential urinary bladder augmentation: proof of concept study in a Göttingen minipig model
}

Dorothea Leonhäuser ${ }^{1}$, Katja Stollenwerk' , Volker Seifarth ${ }^{1,2}$, Isabella M. Zraik ${ }^{1}$, Michael Vogt ${ }^{3}$, Pramod K. Srinivasan ${ }^{4}$, Rene H. Tolba ${ }^{4 \dagger}$ and Joachim O. Grosse ${ }^{1 *+}$

\begin{abstract}
Background: The repair of urinary bladder tissue is a necessity for tissue loss due to cancer, trauma, or congenital abnormalities. Use of intestinal tissue is still the gold standard in the urological clinic, which leads to new problems and dysfunctions like mucus production, stone formation, and finally malignancies. Therefore, the use of artificial, biologically derived materials is a promising step towards the augmentation of this specialised tissue. The aim of this study was to investigate potential bladder wall repair by two collagen scaffold prototypes, OptiMaix 2D and 3D, naïve and seeded with autologous vesical cells, as potential bladder wall substitute material in a large animal model.

Methods: Six Göttingen minipigs underwent cystoplastic surgery for tissue biopsy and cell isolation followed by implantation of unseeded scaffolds. Six weeks after the first operation, scaffolds seeded with the tissue cultured autologous urothelial and detrusor smooth muscle cells were implanted into the bladder together with additional unseeded scaffolds for comparison. Cystography and bladder ultrasound were performed to demonstrate structural integrity and as leakage test of the implantation sites. Eighteen, 22, and 32 weeks after the first operation, two minipigs respectively were sacrificed and the urinary tract was examined via different (immunohistochemical) staining procedures and the usage of two-photon laser scanning microscopy.
\end{abstract}

Results: Both collagen scaffold prototypes in vivo had good ingrowth capacity into the bladder wall including a quick lining with urothelial cells. The ingrowth of detrusor muscle tissue, along with the degradation of the scaffolds, could also be observed throughout the study period.

Conclusions: We could show that the investigated collagen scaffolds OptiMaix 2D and 3D are a potential material for bladder wall substitution. The material has good biocompatible properties, shows a good cell growth of autologous cells in vitro, and a good integration into the present bladder tissue in vivo.

Keywords: Tissue engineering, Urinary bladder, Collagen scaffold, Autologous cell seeding, Large animal model

\section{Background}

Numerous tissue engineering strategies have been developed over recent years in an attempt to generate a urinary bladder wall substitute that would be applicable for

\footnotetext{
*Correspondence: jgrosse@ukaachen.de

${ }^{\dagger}$ Rene H. Tolba and Joachim O. Grosse contributed equally to this work

1 Department of Urology, RWTH Aachen University Hospital,

Pauwelsstraße 30, 52074 Aachen, Germany

Full list of author information is available at the end of the article
}

patients suffering from malfunctions, cancer or trauma [1-7]. The experimental investigation of a broad range of differing materials for vesical augmentation reflects the ongoing challenge for sufficient medical treatment concerning malfunctions of the urinary bladder. As the bladder is a complex organ, this aim is hard to achieve. The storage and voiding functions are regulated by an intricate network of different tissues, nerve tracts, transport proteins and receptors [8-10]. Considering the 
relative complexity of this tissue, it is not surprising that the clinical gold-standard, the usage of absorptive intestinal material, is sub-optimal for long-term treatments, and the need for an equivalent bioengineered alternative apparent [11].

Non-degrading materials such as polytetrafluorethylene $\left(\right.$ Teflon $\left.{ }^{\circledR}\right)$, silicone or polyurethane were only briefly considered as they led to chronic inflammatory reactions, promoted urinary tract infections, calcifications as well as fistula formation [12-15]. For this reason, mainly biodegradable materials, naturally or artificially derived, came into focus within the last years. Processed tissue such as bladder acellular matrix grafts (BAMG) or commercially available small intestinal submucosa (SIS) have provided a range of different outcomes $[4,6,15,16]$. Furthermore, SIS was found to induce immune reactions as foreign DNA remnants could be detected in the material. Moreover, the problem of batch-to-batch variations and alterations due to different processing techniques arises and can lead to an instable outcome after the implantation [17-19].

Artificially engineered scaffolds can be designed adjusted for desired task and tissue. Furthermore, a modification with growth factors or the use as drug delivery system is viable and can further enhance ingrowth of the biomaterial into the host tissue. Especially vascular endothelial growth factor (VEGF) showed promising results in some recent studies but also the graftage with recognition patterns for cells like arginine-glycineaspartic acid (RGD) or isoleucine-lysine-valine-alanine-valine (IKVAV) is feasible [20-23]. Furthermore, the raw materials like polyglycolic acid (PGA), polylactic acid (PLA) or polycaprolactone (PCL) are FDA-approved and commercially available in adequate amounts [24-26]. Drawback of these materials however is that they are foreign to the body and are degraded under generation of acids, which can enhance rejection of the implant [15]. Additionally it has to be granted, that the artificial added molecules are not able to promote tumour development [6].

The use of extracellular matrix-derived components, such as collagen, for scaffold production presents advantages over synthetic polymers and has shown great promise in a number of models of tissue engineering for regenerative medicine [27-31]. Collagen is degraded by enzymes and the degradation products do not interact negatively with the surrounding tissue but, because of its phylogenetic affinity, can be transformed by the organism [6]. In the present study, we selected two differently manufactured collagen type I/III scaffold prototypes, manufactured by Matricel GmbH (Herzogenrath, Germany), after an iterative process of several examinations [32-34]. The company's main product, a sponge-like collagen scaffold (OptiMaix 3D ${ }^{\circledR}$ ), has already been used in different approaches of tissue engineering for diverse organs, such as esophagus, cartilage, vascular and smooth tissue, with promising outcomes [26-31]. The aim of this study was to compare the regenerative potential of collagen scaffolds with a relatively simple, planar or sheetlike form (i.e. OptiMaix $2 \mathrm{D}^{\circledR}$ ), with the structurally more complex, orientated porous form (OptiMaix 3D) in a large animal model. Furthermore, the influence of prior cell seeding on scaffold-host integration and bladder tissue repair was also investigated. The employed Göttingen minipig race is a small pig, especially bred for experimental studies. It is widely regarded as an excellent model for urological research because the micturition volume and voiding frequency closely resemble that of humans as we could demonstrate recently. [35]. Here, we present our first data about the OptiMaix 2D and 3D, naïve and seeded with autologous urothelial (UCs) and detrusor smooth muscle cells (SMCs).

\section{Methods \\ Study design}

Six adult female Göttingen minipigs aged $17.8 \pm$ 1.0 months with an average weight of $44.8 \pm 3.9 \mathrm{~kg}$ (mean $\pm \mathrm{SD}$ ) were obtained from a specific pathogen-free (SPF) breeding facility (Ellegaard Göttingen Minipigs A/S, Dalmose, Denmark) and clinically examined by a veterinarian after arrival. All animals were acclimatized for at least 14 days prior to the study.

In a first operation (OPI), two OptiMaix 2D and two OptiMaix 3D without cells were implanted into the ventral urinary bladder wall of a Göttingen minipig. The excised bladder tissue was used for the isolation and tissue culturing of UCs and SMCs (see below). Scaffolds were seeded with autologous tissue cultured UCs and SMCs after 3 weeks, and remained in an incubator for another three weeks prior to the implantation. During operation II (OPII), one of the implanted OptiMaix 2D and 3D scaffolds, was excised and substituted by an appropriate, freshly prepared naïve 2D or 3D scaffold of the same shape. Accordingly, an initial assessment of implant-host integration after 6 weeks was possible. Additionally, two cell-seeded OptiMaix 2D scaffolds were implanted into the right, and one cell-seeded OptiMaix 3D scaffold was implanted into the left dorsal bladder wall (Fig. 1).

At weeks 18, 22 and 32 (i.e. 12, 16 and 26 weeks after OPII), two minipigs were sacrificed and the urinary tract examined. These time points were chosen due to results of two Göttingen minipigs in a preliminary study. The degradation of the scaffolds should have been accomplished at 14-15 weeks after the implantation, according to the assumption of the scaffold's manufacturer. Instead, 


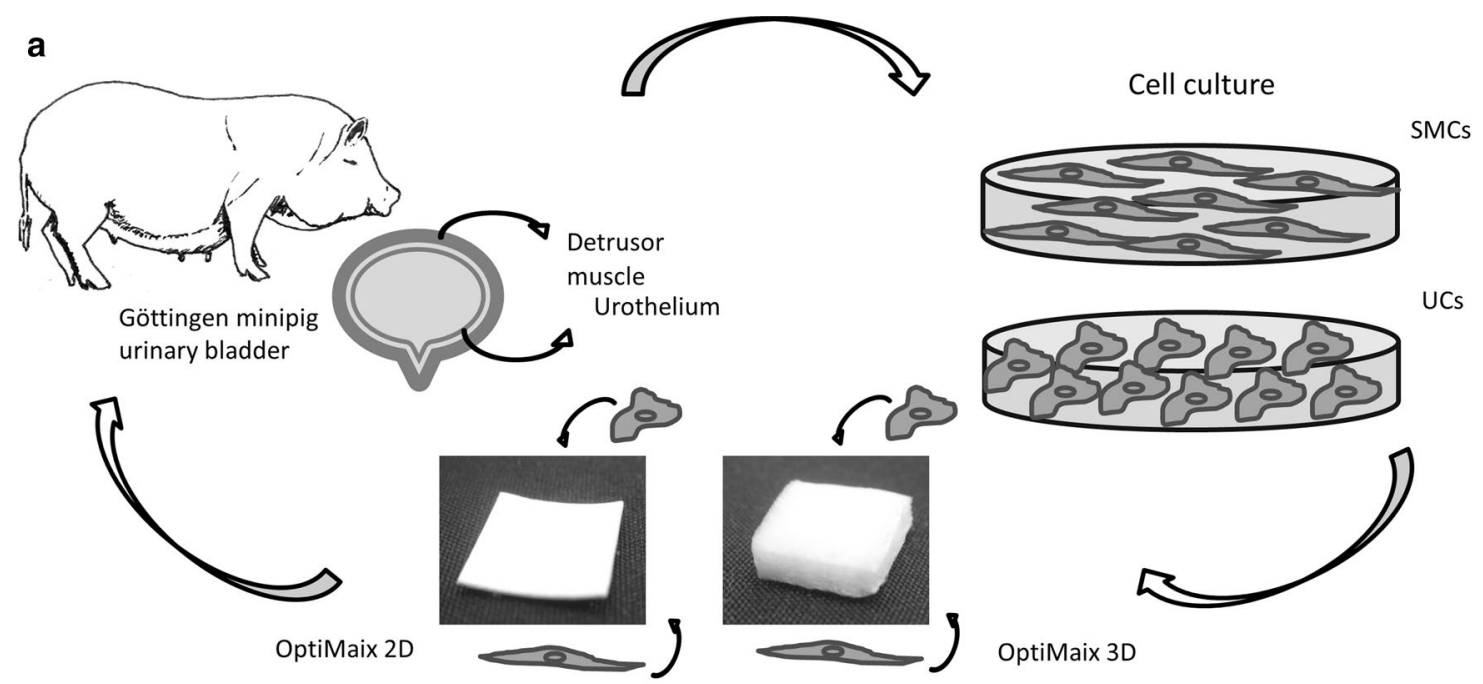

b

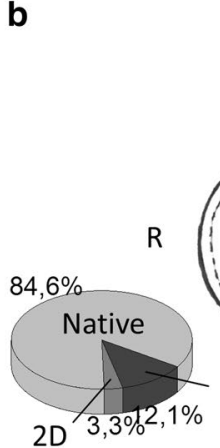

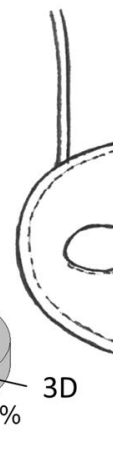

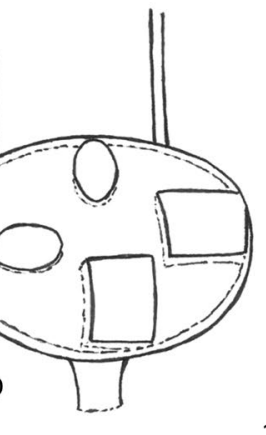

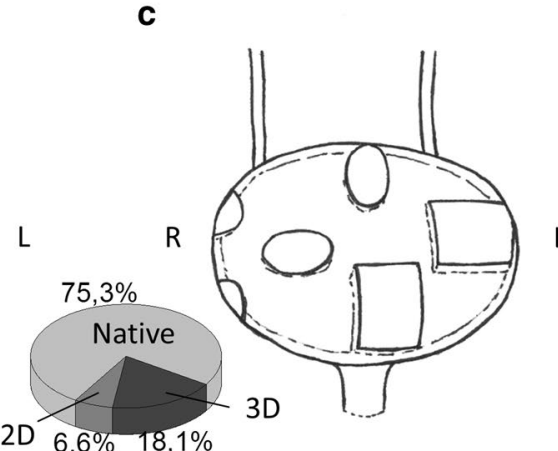

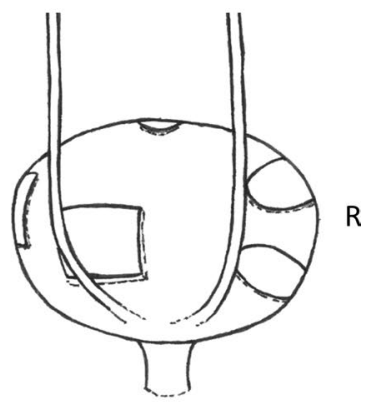

Fig. 1 Study design. a Isolation and cultivation of primary cells from Göttingen minipig urinary bladder. Seeding of scaffolds was performed after 3 weeks and implantation of seeded scaffolds into the pig bladder after another 3 weeks. b During OPI two OptiMaix 2D (oval) and 3D (square) each, without cells, were implanted into the ventral bladder wall. c During OPII, one of the implanted OptiMaix 2D and 3D each, was excised and substituted by a fresh unseeded scaffold of the same make and shape. Two autologously seeded OptiMaix 2D scaffolds were implanted into the right and one autologously seeded OptiMaix 3D scaffold was implanted in the left dorsal bladder wall. After OPI 15.4\% and after OPII 24.7\% of the native tissue had been substituted by the OptiMaix scaffolds

pieces of the artificial collagen could still be found. Therefore, one time point before and one after this first time limit, as well as one after a longer period, namely 12,16 and 26 weeks after OPII were chosen. In addition, by performing two operations in one animal, more information about the timescale of implant-host tissue integration could be obtained in accordance with the 3R-principle. The study design is presented schematically in Fig. 2.

\section{Surgical procedure}

OptiMaix 2D scaffolds were appropriately trimmed to fit the custom made, oval Teflon seeding rings $\left(3.3 \mathrm{~cm}^{2}\right)$ immediately before implantation. This pre-cut was performed to have a basis for comparison with the seeded scaffolds, which were implanted in the second operation. The highly porous (pore diameter $\approx 100 \mu \mathrm{m}$ ) OptiMaix 3D scaffolds proved to be fragile and easily damaged, thus necessitating the use of a larger surface for suturing.
The 3D scaffolds were, therefore, implanted and sutured in their delivered format of $3 \times 4 \mathrm{~cm}^{2}(\times 3.0 \mathrm{~mm})$.

Pre-sedation was performed with an i.m. injection of $4 \mathrm{mg} / \mathrm{kg}$ azaperone (Stresnil ${ }^{\circledR}$, Sanochemia Pharmazeutika AG, Neufeld, Austria) and $0.1 \mathrm{mg} / \mathrm{kg}$ atropine (Dr. Franz Köhler Chemie GmbH, Bensheim, Germany). A second i.m. injection with $10 \mathrm{mg} / \mathrm{kg}$ ketamine (Ceva, Düsseldorf, Germany) was administered after $15 \mathrm{~min}$. Blood samples were taken from all animals for routine blood counts. Anaesthesia was subsequently deepened by an i.v. injection of $1 \mathrm{mg} / \mathrm{kg}$ propofol (Fresesnius Kabi, Bad Homburg, Germany) and the animals were intubated. Inhalation anaesthesia was maintained with $1-1.5 \mathrm{vol} \%$ of isoflurane (Forene ${ }^{\circledR}$, abbvie, Darmstadt, Germany). A continuous infusion of fentanyl $(0.02 \mathrm{mg} / \mathrm{kg} \mathrm{h}$, Rotex Medica GmbH, Trittau, Germany) was also administered to ensure analgesia. Additional volume demand during laparotomy was compensated with an infusion of $0.9 \%$ 


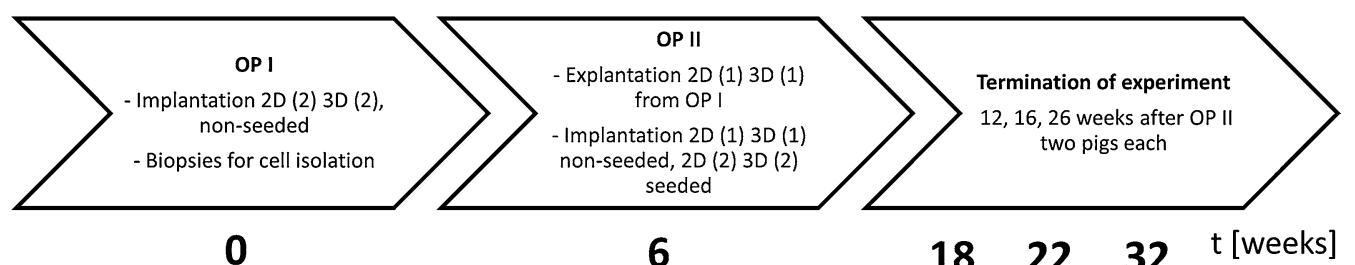

0

6

$18 \quad 22 \quad 32$

Fig. 2 Timeline of the in vivo study. During OPI biopsies were taken for cell cultivation and unseeded scaffolds were implanted. Six weeks later, two scaffolds implanted in OPI were excised for histological evaluation and fresh unseeded as well as autologously seeded scaffolds were implanted. Termination of the experiment was at 18,22 and 32 after OPI. Number in brackets gives the quantity of implanted scaffolds

sodium chloride solution (B. Braun, Melsungen, Germany) with a rate of $4 \mathrm{ml} / \mathrm{kg} \mathrm{h}$.

A midline incision of the lower abdomen was performed after cleaning and disinfection of the operation field. The pigs were provided with a transurethral catheter and the urinary bladder was lifted above the symphysis by filling it with $200 \mathrm{ml} 0.9 \%$ sodium chloride solution. Urothelial and detrusor muscle tissue of the designated implantation sites was sharp-dissected with scalpel and scissors while simultaneously creating a serosal flap (Fig. 3b). The biopsies, which corresponded in size to that of the intended implants (i.e. $0.8 \times 1.4 \mathrm{~cm}^{2}$ for the ellipsoid 2D scaffold and $3.0 \times 4.0 \mathrm{~cm}^{2}$ for the $3 \mathrm{D}$ scaffold) were transferred to a sterile cup containing pre-warmed "modified Eagle's Medium" (MEM, Life Technologies, Braunschweig, Germany) and immediately processed in the cell culture facility (see below). Collagen scaffolds were implanted and secured in the prepared lesion sites with resorbable PDS II 4-0 sutures (Johnson \& Johnson, Medical GmbH, Norderstedt, Germany, Fig. 3c). Non-absorbable marking sutures were set with Prolene 3-0 (Johnson and Johnson) at four corners of the scaffold (Fig. 3d) using black suture for the 2D scaffold and blue for the 3D scaffold. The remaining serosal flap was used to cover the scaffold and was fixed with PDS II 4-0 (Fig. 3e). The bladder was then filled with $0.9 \%$ sodium chloride solution to check for leakage. The peritoneum, muscle, and subcutis were closed separately with Vicryl 2-0 sutures (Johnson and Johnson) and the skin closed with Prolene 2-0 sutures (Johnson and Johnson). A fresh transurethral catheter was placed to avoid pressure on the healing bladder tissue. Prophylactic antibiotics (Cefuroxime $500 \mathrm{mg}$, Heumann Pharma GmbH \& Co., Nürnberg, Germany) were given twice daily and Carprofen (Rimady ${ }^{\circledR}, 4 \mathrm{mg} / \mathrm{kg}$ body weight, Pfizer Deutschland $\mathrm{GmbH}$, Berlin, Germany) was given once daily for analgesia via oral administration for five days.

\section{Post-operative care}

The health status of the animals was checked every day. Assessment of urinary bladder integrity was performed via cystography after one week. For this, minipigs were sedated as described above and up to $350 \mathrm{ml}$ of radiocontrast medium (Conray ${ }^{\mathrm{TM}}$, Mallinckrodt pharmaceuticals, Dublin, Ireland) was infused into the bladder via the transurethral catheter. In case of leakage, a fresh transurethral catheter remained in the bladder until a second follow-up after 1 week.

After removal of the catheter, the minipigs were observed in a metabolic cage for $24 \mathrm{~h}$ with regular diet and controlled water ad libitum. This monitoring was also done prior to and after each operation as well as the termination of the experiment to evaluate the bladder function. Proof of the time point and volume of the micturition was ensured by video monitoring (Mobotix, Langmeil, Germany) and an urological flow meter consisting of a scale with a collecting vessel and corresponding software (Flow, Laborie, Montreal, Quebec, Canada) as described elsewhere [36].

\section{Cell culture of UCs and SMCs}

Autologous UCs and SMCs were isolated as described previously [37]. Briefly, the urothelium and detrusor muscle were dissected from the bladder biopsy and the cells mechanically dissociated. After gentle agitation $\left(1 \mathrm{~h}\right.$ at $37^{\circ} \mathrm{C}$ ) in MEM with $400 \mu \mathrm{g} / \mathrm{ml}$ collagenase (Liberase $^{\circledR}$, Roche Applied Sciences, Penzberg, Germany) the cell suspension was filtered through a stainless steel mesh $\left(1.0 \mathrm{~mm}^{2}\right.$ pore size), washed three times with MEM containing $10 \%(\mathrm{v} / \mathrm{v})$ fetal calf serum (FCS, Thermo Scientific) and transferred in collagen-coated (Biochrom AG, Berlin, Germany) cell culture flasks (Nunclon ${ }^{\mathrm{TM}}$, Thermo Scientific). The UCs were cultured in Keratinocyte-SFM (Life Technologies) and SMCs in a selection medium described elsewhere in a humidified incubator with $5 \% \mathrm{CO}_{2}$ at $37{ }^{\circ} \mathrm{C}$ [32]. The selection medium was used for 3 days to inhibit the growth of fibroblasts in the SMC population. For the subsequent cultivation, SMCs were treated with smooth muscle cell growth medium 2 (Promo Cell GmbH, Heidelberg, Germany). The cultured cells were regularly monitored via a Leica DMI 4000B (Leica Microsystems GmbH, Wetzlar, Germany) and integrated software (Diskus 4.80.5909, Hilgers, Technisches Büro, Königswinter, Germany). 


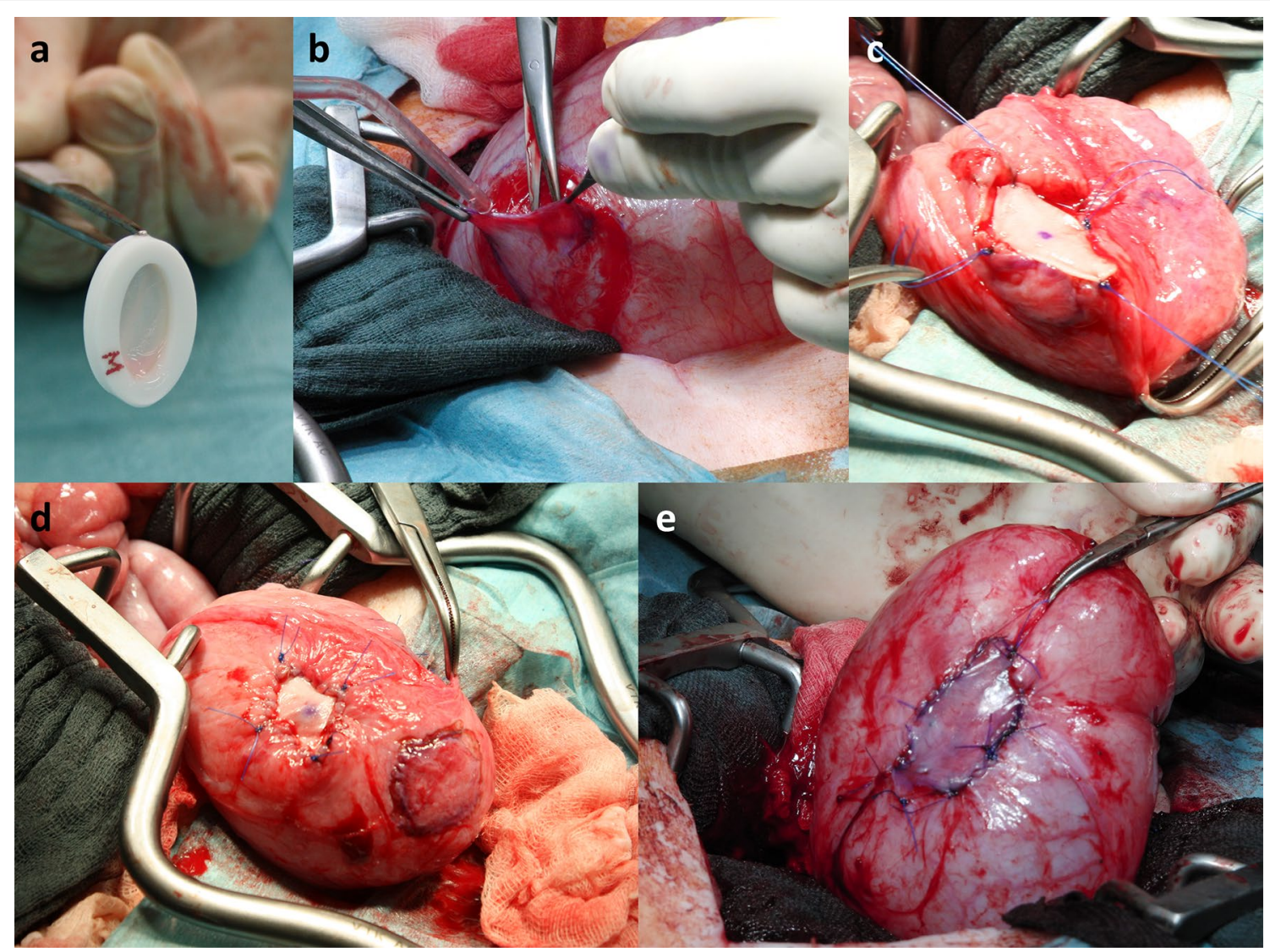

Fig. 3 Implantation procedure of a seeded OptiMaix 2D into the minipig bladder. a Seeded OptiMaix 2D in the custom made seeding ring. $\mathbf{b}$ Creation of the serosal flap. c Setting of marks with non-degradable sutures. d Implanted OptiMaix 2D. e Sealed implantation site. Implantation of OptiMaix 3D was performed similarily (not shown)

\section{Cell-seeding and implantation of OptiMaix scaffolds}

OptiMaix 2D scaffolds were fixed in the custom made seeding rings and seeded with SMCs. As mentioned above, OptiMaix 3D scaffolds could not as planned be cut to the size of the seeding ring, and therefore, were laid flat in a petri dish and then seeded similarily to the OptiMaix 2D. After $4 \mathrm{~h}$, the petri dishes were filled with MEM containing $20 \%$ FCS and $1 \%$ amphotericin B and $1 \%$ gentamicin. For co-culture, one day later, SMCseeded scaffolds were placed in a fresh petri dish and UCs were seeded onto the other side of the scaffold. An additional scaffold of each type was seeded to serve as a control for cell growth. Medium was changed every second day.

\section{Histochemical and immunohistochemical staining of scaffolds}

Two times a week ( $\mathrm{d} 1$ and $\mathrm{d} 4$ ), a piece of $3 \mathrm{~mm}$ width of the seeded control scaffolds was cut off and fixed in Carnoy's Solution [60\% ethanol (Merck, Darmstadt, Germany), 30\% chloroform, 10\% acetic acid (both Carl Roth GmbH
\& Co.KG, Karlsruhe, Germany)] for $4 \mathrm{~h}$. The fixed samples were dehydrated through ascending concentrations of ethanol, paraffin embedded and cut into $3 \mu \mathrm{m}$ sections. For subsequent staining, sections were deparaffinized and rehydrated in descending concentrations of ethanol, eventually being washed in PBS. Sections were stained with haematoxylin-eosin (HE), 4',6-Diamidin-2-phenylindol (DAPI) and nuclear fast red-fast green (RG).

Immunohistochemistry with pancytokeratin (PanCK) and $\alpha$-smooth muscle actin ( $\alpha$-SMA) was performed as described previously using the antibodies mentioned in Table 1 [37]. Briefly, sections were deparaffinized in descending ethanol solutions. The antigen retrieval was performed using citrate-buffer (Zytomed System GmbH, Berlin, Germany) in a steamer for $30 \mathrm{~min}$, and primary antibodies, diluted in PBS, were incubated for $1 \mathrm{~h}$. The secondary antibody and chromogen development was performed using the DAKO Real EnVision HRP rabbit/ mouse with $\mathrm{DAB}$. Images of the stainings were generated using a Leica DM6000B with external light source for fluorescence excitation Leica EL6000 and integrated 
Table 1 Antibodies for immunohistochemical staining of control scaffolds and excised bladder biopsies

\begin{tabular}{llll}
\hline Antibody & Clone number & Dilution & Company \\
\hline a-Smooth muscle actin & 1 A4 & $1: 400$ & Dako GmbH, Hamburg, Germany \\
PanCK & AE1/AE3 & $1: 300$ & Dako GmbH, Hamburg, Germany \\
CD34 & QBEnd-10 & $1: 200$ & Antibodies-Online GmbH, Aachen, Germany \\
VEGF & VG76e & $1: 200$ & Antibodies-Online GmbH, Aachen, Germany \\
S100 & Z0311 & $1: 1000$ & Dako GmbH, Hamburg, Germany \\
\hline
\end{tabular}

software (Diskus 4.80.5909, Hilgers, Technisches Büro, Königswinter, Germany).

\section{Termination of the experiment}

The minipigs were anaesthetized as mentioned above. Final examination of bladder integrity, shape, and urinary reflux were performed via ultrasound and bladder filling with $0.9 \%$ sodium chloride solution.

The pigs were then euthanized by i.v. injection of $0.16 \mathrm{~g} / \mathrm{kg}$ barbiturate $\left(\right.$ Narcoren $^{\circledR}$, Merial, Hallbergmoos, Germany). The urinary bladder and kidneys with ureters were removed and weighed. The urinary bladder was fixed for $24 \mathrm{~h}$ and kidneys with ureters were fixed for seven days in $4 \%$ phosphate buffered formaldehyde (Merck).

The whole bladder was processed for histological evaluation with emphasis on the implantation sites. Three sections of the kidney including cortex and medulla, the renal pelvis, as well as the proximal and distal ureters were examined for signs of pathological alterations. The implanted scaffolds were processed in the same manner as the cell-seeded scaffolds (described above). This involved sample dehydration, paraffin embedding and $3 \mu \mathrm{m}$ sections being prepared. The histochemical staining of the bladder wall was performed using Elastica van Giesson's staining (EVG) to provide an overview of the general morphology of the implantation site. PanCK was used to identify the urothelial layer, $\alpha$-SMA was used for control of the detrusor muscle structure, cluster of differentiation 34 (CD34) and VEGF to identify blood vessels for vascularization and $\mathrm{S} 100$ as an indirect indicator of nerve fibre distribution (antibodies see Table 1). All staining methods were performed as mentioned above.

\section{Two-photon laser scanning microscopy (TPLSM)}

In an attempt to evaluate the extent of implanted scaffold degradation, unstained sections were examined using a two-photon microscope (FV1000MPE, Olympus Corp., Tokyo, Japan) attached to a pulsed Ti-Sapphire laser (MaiTai DeepSee, SpectraPhysics) with a $25 \times$ water immersion objective (1.05NA, WD2.0). For excitation of the collagen remnants inside the tissue, the laser was tuned to the wavelength of $750 \mathrm{~nm}$. The emission autofluorescent signals were collected with bandpass filters at $419-465,495-540$ and $590-650 \mathrm{~nm}$, respectively. The intense autofluorescent structure of the scaffold was mainly detected in the range of 419-465 and 495$540 \mathrm{~nm}$. Further image processing was performed using Image J (Version 1.49j10, National Institutes of Health, USA).

\section{Statistics}

Data analysis of micturition volumes was performed using Origin (9.1 OG, 1991-2013 Origin Lab Corporation, Northampton, USA). All results are shown as mean \pm SD. All examined data was tested for normal distribution by the Shapiro-Wilks test. Statistical differences were determined via One-way ANOVA with Tukey Post-Hoc test. $\mathrm{P} \leq 0.05$ was considered to be statistically significant.

\section{Results}

Seeding of scaffolds

Cell isolation resulted in differing cell cultivation counts based on intraindividual conditions of the animals. Nevertheless, all isolations were successful and a an average cell yield of $4.5 \times 10^{6} \mathrm{UCs}$ and $2.9 \times 10^{7} \mathrm{SMCs}$ could be seeded onto the scaffolds resulting in a distribution of $2.4 \times 10^{5}(\mathrm{UCs})$ and $1.6 \times 10^{6}(\mathrm{SMCs})$ per $\mathrm{cm}^{2}$. The SMCs were building a multilayer on top of the structured side of the OptiMaix 2D as the fibres of the scaffold were deflating when in contact with the cell culture medium (Fig. 4a). After 3 days, a closed layer of UCs was visible on the dense side of the OptiMaix 2D scaffold. After 2 weeks in culture, layers up to three cells thick could be observed in histological sections (Fig. 4b). The OptiMaix 3D scaffold allowed both UCs and SMCs to penetrate, adhere and grow inside the longitudinally orientated micropores of the 3D scaffold. Since these micro-pores had an average diameter of $100 \mu \mathrm{m}$, cells usually appeared to be associated with the walls of the porous framework rather than filling the pores.

\section{Surgery}

The scaffold material of OptiMaix 2D had an appearance and texture similar to wet chamois and could, therefore, 


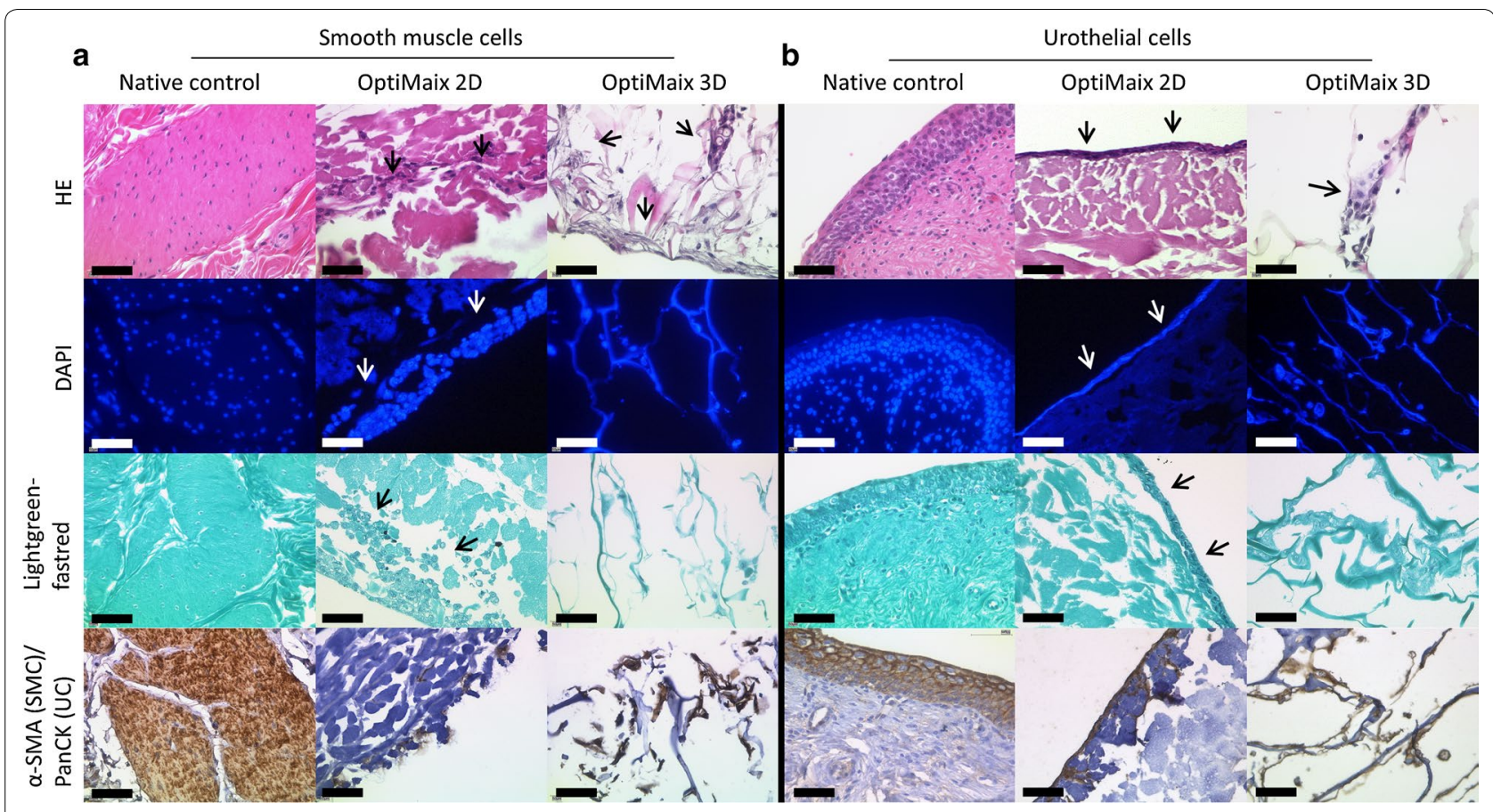

Fig. 4 OptiMaix 2D and 3D seeded with (a) SMCs and (b) UCs before implantation. SMCs are building a multilayer on top of the fibres of the structured side of OptiMaix 2D (arrows) but are migrating inside the open pores of OptiMaix 3D. UCs are lining the dense side of OptiMaix 2D (arrows). Due to the open structure of OptiMaix 3D, UCs are also infiltrating the scaffold. Scale bar $=50 \mu \mathrm{m}$

be easily sutured into the urinary bladder wall. In contrast, the OptiMaix 3D, was more delicate because of its highly porous structure. Preliminary attempts to suture the 3D scaffold in the same precut oval shape as the 2D failed due to rupturing of the scaffold at the suture points. This technical difficulty was overcome by using the whole $3 \times 4 \mathrm{~cm}^{2}$ scaffolds that could be successfully sutured into the wall of the bladder. Instead of three small scaffolds, now only two original-sized 3D scaffolds were implanted.

All six animals recovered well after surgery and the analysis of blood parameters showed no signs of inflammation or infection. As a reaction to the blood loss that occurred during the operations, the number of thrombocytes had increased and haemoglobin and haematocrit values had decreased. These values returned to normal levels by the end of the experiment (Table 2). Although there was a tendency for reduced micturition volume at 6 weeks (the time point of OPII) there was no statistically significant reduction of volumes at any survival time studied (Fig. 5). There were no signs of incontinence or infections of the urinary tract. Cystography revealed that the implantation sites of the OptiMaix 3D scaffolds had a greater potential for leakages than the 2D scaffolds which occurred in two of the six pigs. The bladder shape was influenced by the multiple implants leading to slightly pear-shaped urinary bladders. However, by the end of the experiment, the bladder demonstrated a normal shape (Fig. 6). There was no urinary reflux to the kidneys. Before each operation and at the termination of the experiment, only ultrasound was performed, since the contrast agent lead to oedema in the bladder urothelium.

\section{Histological evaluation}

The serosa mainly was a homogenous closed layer, solely, the usage of different coloured non-degradable marking sutures allowed a macroscopic differentiation of OptiMaix 2D and 3D scffolds. However, the marking sutures favoured adhesion of the bladder serosa to the omentum and surrounding organs and had to be carefully dissected during the removal of the urinary tract at the end of the experiment. Bladder weight was in the range of $89.5 \pm 16.2 \mathrm{~g}$, the left kidney had an average weight of $105.5 \pm 22.2 \mathrm{~g}$ and the right kidney of $108.5 \pm 26.8 \mathrm{~g}$. After 32 weeks, the implantation sites were still visible on the interior surface. No macroscopic anomalies of the urinary tract were visible. Kidneys and ureters were without any pathological alteration, no kidney reflux occurred and the bladder was without calcifications or stone formation.

At week six, the scaffold structure seemed nearly intact but the degradation process had already started. 
Table 2 Blood and renal parameters of Göttingen minipigs

\begin{tabular}{|c|c|c|c|c|c|c|}
\hline Kidney values (serum) & $\begin{array}{l}\text { OP I } \\
\text { O weeks }\end{array}$ & $\begin{array}{l}\text { After OP I } \\
2 \text { weeks }\end{array}$ & $\begin{array}{l}\text { OP II } \\
6 \text { weeks }\end{array}$ & $\begin{array}{l}\text { After OP II } \\
8 \text { weeks }\end{array}$ & $\begin{array}{l}\text { Termination } \\
\text { 18/22/32 weeks }\end{array}$ & Norm \\
\hline Total protein (g/dl) & $6.4 \pm 0.7$ & $5.2 \pm 0.5$ & $6.7 \pm 0.5$ & $6.1 \pm 0.3$ & $6.5 \pm 0.7$ & $4.5-8.5$ \\
\hline Urea $(\mathrm{mmol} / \mathrm{l})$ & 2.4. \pm 1.1 & $1.8 \pm 0.1$ & $2.2 \pm 0.9$ & $3.7 \pm 3.7$ & $2.2 \pm 0.9$ & $3.3-8.3$ \\
\hline Creatinine $(\mu \mathrm{mol} / \mathrm{l})$ & $107.5 \pm 13,8$ & $78.4 \pm 16.7$ & $119.3 \pm 20.8$ & $127.8 \pm 73.6$ & $107.7 \pm 19.5$ & $40-133$ \\
\hline Uric acid ( $\mu \mathrm{mol} / \mathrm{l})$ & $14.0 \pm 0.7$ & $13.8 \pm 0.8$ & $13.5 \pm 0.8$ & $14.5 \pm 1.8$ & $14.0 \pm 0$ & - \\
\hline Sodium (mmol/l) & $143.8 \pm 1.7$ & $141.2 \pm 1.3$ & $141.7 \pm 8.3$ & $144.0 \pm 1.7$ & $142.5 \pm 2.7$ & $140-160$ \\
\hline Potassium (mmol/l) & $3.7 \pm 0.3$ & $3.7 \pm 0.4$ & $3.6 \pm 0.7$ & $3.9 \pm 0.5$ & $3.7 \pm 0.3$ & $4.0-5.0$ \\
\hline Chloride (mmol/l) & $101.5 \pm 2.1$ & $99.0 \pm 1.4$ & $100.0 \pm 0.9$ & $99.0 \pm 2.4$ & $101.5 \pm 0.6$ & $102-106$ \\
\hline \multicolumn{7}{|l|}{ Blood count } \\
\hline Leucocytes $\left(\times 10^{3} / \mu \mathrm{l}\right)$ & $7.2 \pm 1.6$ & $7.5 \pm 2.1$ & $7.6 \pm 4.7$ & $11.9 \pm 6.7$ & $7.5 \pm 4.0$ & $7.0-22.0$ \\
\hline Erythrocytes $\left(\times 10^{6} / \mu \mathrm{l}\right)$ & $5.8 \pm 0.7$ & $5.0 \pm 0.9 \downarrow$ & $7.1 \pm 2.3$ & $4.5 \pm 1.1 \downarrow$ & $5.5 \pm 0.9$ & $5.8-8.0$ \\
\hline Thrombocytes $\left(\times 10^{3} / \mu \mathrm{l}\right)$ & $507.7 \pm 93.1$ & $699.0 \pm 179.9 \uparrow$ & $371.7 \pm 171.3$ & $819.3 \pm 236.8 \uparrow$ & $554.0 \pm 142.0$ & $175-587$ \\
\hline Haemoglobin (g/dl) & $11.6 \pm 1.1$ & $10.5 \pm 1.7$ & $14.2 \pm 4.1$ & $9.2 \pm 1.9 \downarrow$ & $11.1 \pm 0.9$ & $10.0-16.0$ \\
\hline Haematocrit (\%) & $32.2 \pm 2.3$ & $29.1 \pm 4.2 \downarrow$ & $39.0 \pm 10.9$ & $25.8 \pm 5.3 \downarrow$ & $30.9 \pm 2.5$ & $33.0-45.0$ \\
\hline $\mathrm{MCV}(\mathrm{fl})$ & $56.0 \pm 6.1$ & $58.3 \pm 4.7$ & $56.2 \pm 6.1$ & $57.8 \pm 6.1$ & $56.8 \pm 5.6$ & $50.0-68.0$ \\
\hline $\mathrm{MCH}(\mathrm{pg})$ & $20.2 \pm 2.2$ & $20.9 \pm 1.8$ & $20.5 \pm 2.3$ & $20.5 \pm 2.3$ & $20.4 \pm 2.2$ & $17.0-21.0$ \\
\hline $\mathrm{MCHC}(\mathrm{g} / \mathrm{dl})$ & $36.2 \pm 0.9$ & $35.9 \pm 1.0$ & $36.4 \pm 0.6$ & $35.5 \pm 0.7$ & $36.0 \pm 0.6$ & $30.0-35.0$ \\
\hline \multicolumn{7}{|l|}{ Differential blood count } \\
\hline Unsegmented granulocytes (\%) & $5.0 \pm 1.9$ & $5.8 \pm 1.9$ & $5.8 \pm 3.1$ & $5.3 \pm 2.2$ & $5.2 \pm 3.6$ & $0-7$ \\
\hline Segmented granulocytes (\%) & $31.5 \pm 16.4$ & $33.4 \pm 11.4$ & $33.7 \pm 14.3$ & $36.2 \pm 12.5$ & $26.5 \pm 18.5$ & $10-39$ \\
\hline Lymphocytes (\%) & $54,5 \pm 17,6$ & $51.2 \pm 10.1$ & $54.2 \pm 15.1$ & $43.8 \pm 22.7$ & $60.5 \pm 24.7$ & $49-85$ \\
\hline Monocytes (\%) & $8.0 \pm 3.5$ & $7.6 \pm 2.3$ & $5.5 \pm 1.4$ & $7.0 \pm 2.6$ & $6.7 \pm 2.7$ & $0-5$ \\
\hline Eosinophils (\%) & $0.7 \pm 1.0$ & $1.8 \pm 0.8$ & $0.7 \pm 0.8$ & $0.7 \pm 1.0$ & $1.0 \pm 0.9$ & $0-6$ \\
\hline Basophils (\%) & $0.3 \pm 0.5$ & $0.2 \pm 0.4$ & $0.2 \pm 0.4$ & $0.3 \pm 0.5$ & $0.2 \pm 0.4$ & $0-2$ \\
\hline
\end{tabular}

All results are shown as mean $\pm S D$

No significant differences could be examined

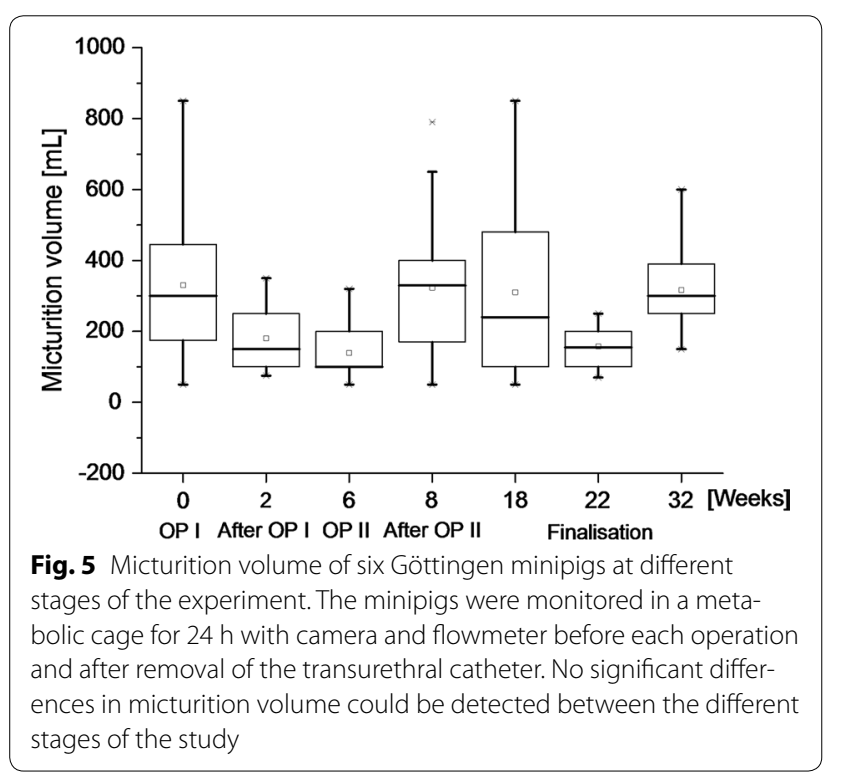

Remnants of the OptiMaix 2D were still visible after 32 weeks. Figures 7 and 8 show this process, as the foreign collagen appears dark violet in the EVG staining. However at this time, a closed urothelial layer with underlying connective tissue was clearly visible on the inner surface of the OptiMaix 2D scaffold. The seeding of urothelial cells on the collagen scaffold here did not seem to have any influence on this process. The detrusor muscle grew from the sides of the implant towards its centre. Here, the dense structure decelerated the ingrowth of the adjacent tissue into the scaffold. Furthermore, pre-seeding with SMCs did not improve the ingrowth process. Nevertheless, until 32 weeks, muscle tissue was growing. The staining with CD34 and VEGF showed enhanced vascularization with blood vessels growing through the scaffold material at six and 18 weeks. This vascularization seemed to become less with 22 weeks and was at a normal level compared to the native control when the 


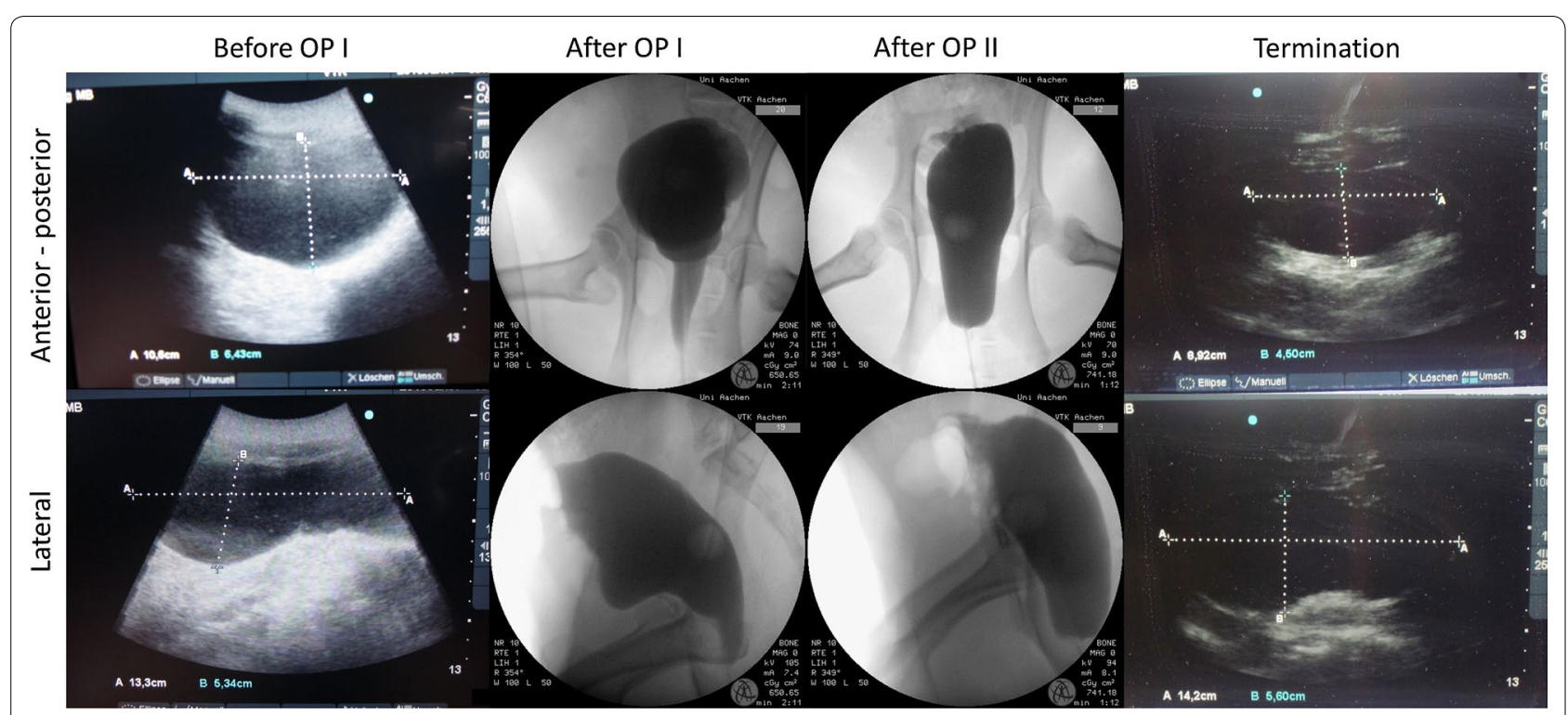

Fig. 6 Ultrasound and cystography of Göttingen minipigs. Cystography was performed post-OP after removal of the transurethral catheter for evaluation of bladder shape and integrity. As the contrast agent lead to oedema, immediately before operations and the termination of the experiment only ultrasound was performed. Filling was performed with $300 \mathrm{ml}$ sodium chloride (0.9\%) and contrast agent respectively

tissue had reorganized itself at 32 weeks. The S100 staining showed a continuous ingrowth of nerve fibres into the new tissue.

OptiMaix 3D remnants could also be found after 32 weeks (Figs. 9, 10). Compared to the dense structure of the $2 \mathrm{D}$ scaffold, after 6 weeks, adjacent connective tissue had grown inside the wide pores of the sponge-like structure. Seeding with cells in this case also did not accelerate this process, but quite the contrary; the seeded $3 \mathrm{D}$ scaffolds seemed to be encapsulated by the surrounding tissue in both pigs at 18 weeks. This phenomenon could not be found in the four pigs housed for 22 and 32 weeks. Here, remnants of the scaffold could favourably be found beneath the urothelium and less in the muscle regeneration zone. As anticipated, the pore structure of the OptiMaix 3D was a disadvantage concerning the urothelium. The urothelial cells, like in vitro, lined the inside of these pores and were not able to build a closed layer on top of the scaffolds. Instead, scattered urothelial clusters had formed inside the scaffold by 6 weeks. This phenomenon was increasing until 18 weeks and abated after 22 weeks. At 32 weeks, the urothelium on top of the scaffold had reorganized in association with ongoing scaffold-degradation, and could clearly be seen as a single, continuous band of cells. Vascularization and nerve-fibre ingrowth were comparable to the OptiMaix 2D scaffold.

TPLSM confirmed the general histological and immunohistochemical observations concerning the degradation of the OptiMaix scaffolds. Remnants could be mainly found in the occlusion zone in the periphery of the implantation sites (Fig. 11). The ingrowth of adjacent tissue into the OptiMaix 2D was clearly less prominent than in the OptiMaix 3D. Yet again, no difference between seeded and unseeded scaffolds could be detected.

\section{Discussion}

The aim of this study was the comparison of two differently manufactured collagen scaffolds OptiMaix as material for bladder wall repair. In this context, the building of a (multi-)layer of cells on both scaffolds with a subsequent good cell growth in vitro speaks for a high biocompatibility. The dense side of the OptiMaix 2D reached a desirable result for the UCs, whereas, the SMCs were only growing on the surface of the scaffold instead of growing in. The OptiMaix 3D in contrast, allowed migration of cells into the scaffold structure, which is not desirable for the UCs. Another issue arising with the OptiMaix 3D was the difficult sewing process during the operations. Regarding this aspect, the OptiMaix 2D was relatively easier to handle and additionally one week after operation, the implantation sites of the $2 \mathrm{D}$ scaffolds were closed. Indicated by cystographies, the implantation sites of the 3D scaffolds needed longer recovery; hence, the pigs were in need of a transurethral catheter for an extended period. These differences in permeability coincide with the findings of Montzka et al. [32] who performed experiments with these scaffolds in an Ussing chamber.

Six pigs with big inter-individual micturition differences were used in our study. Although there were differences 


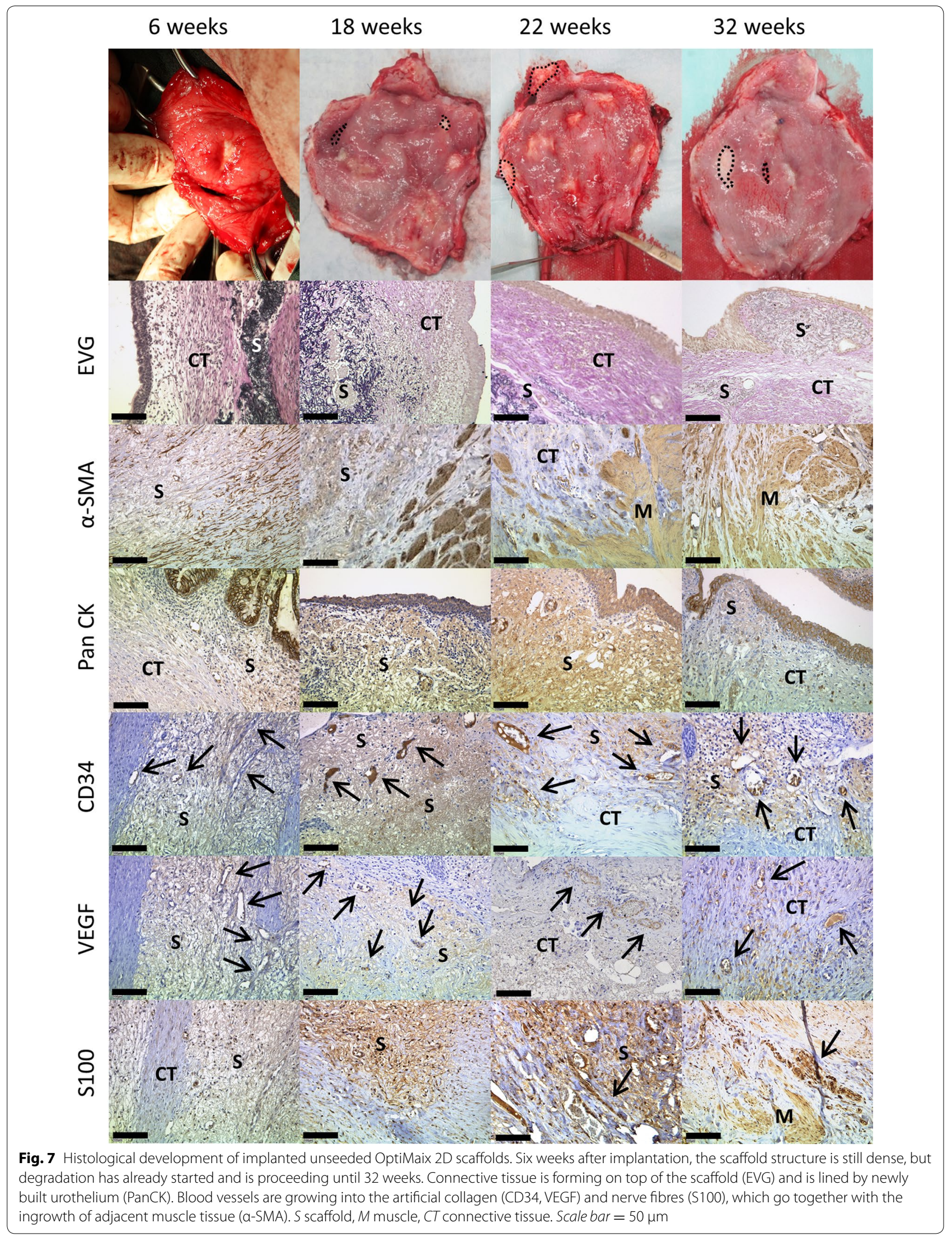




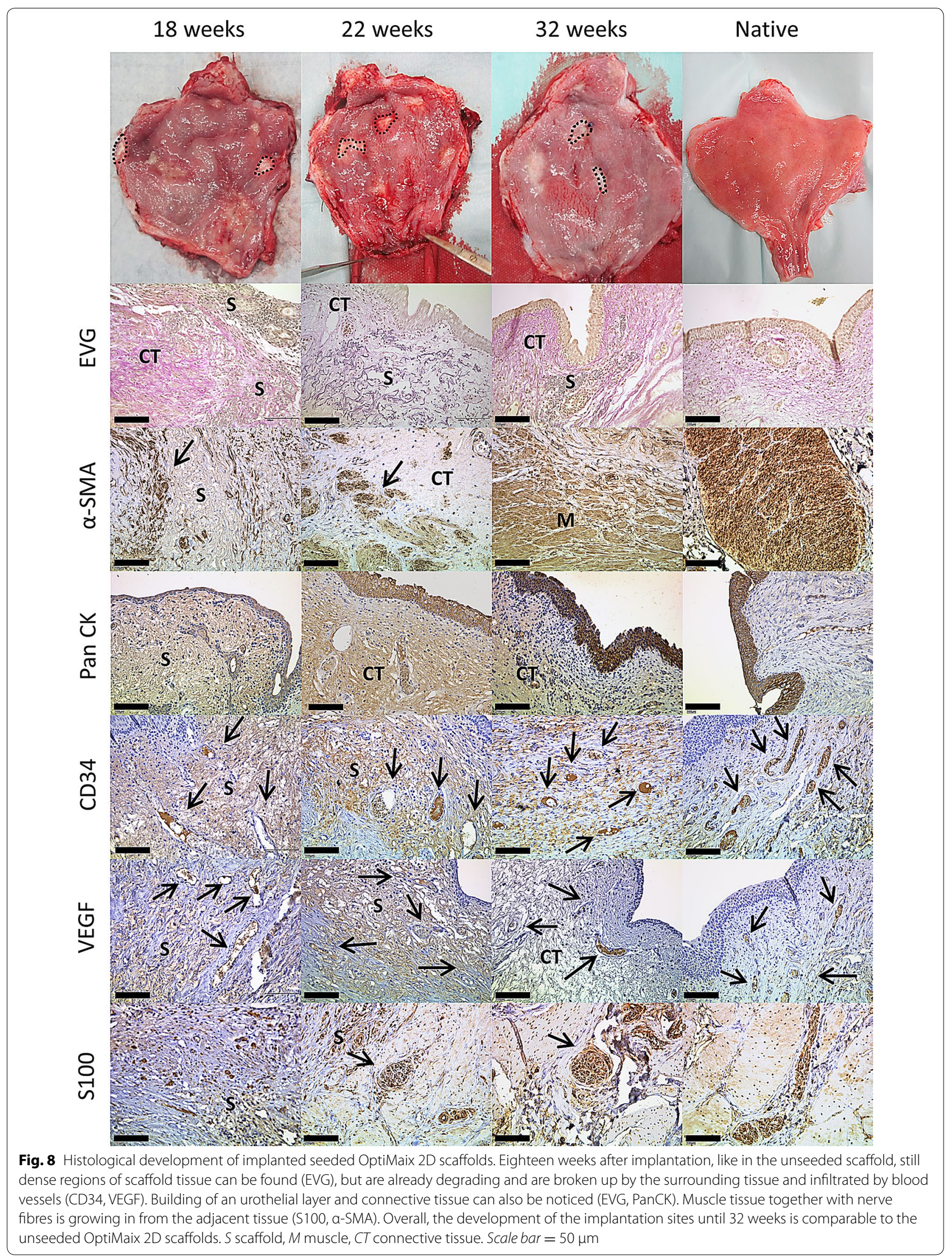




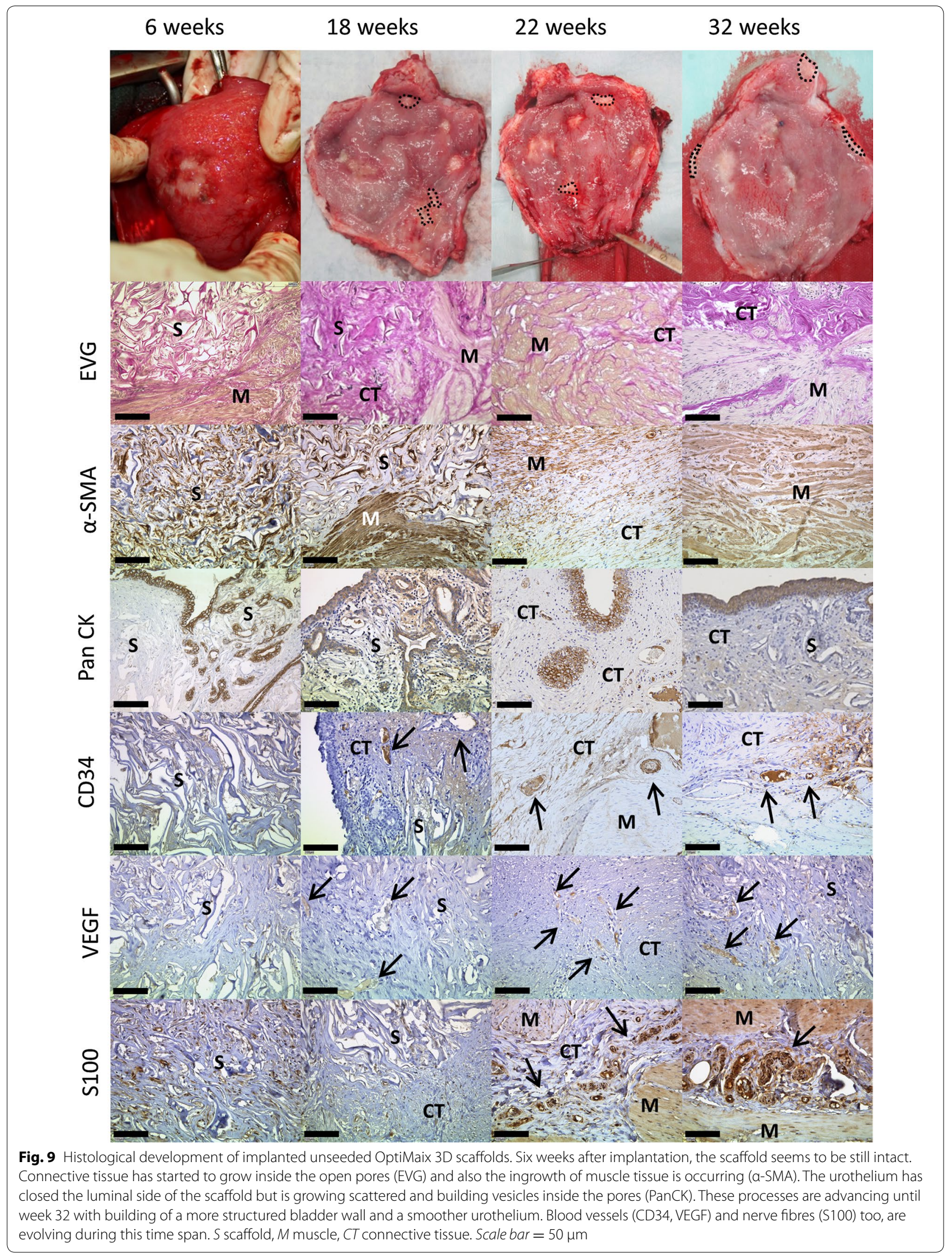




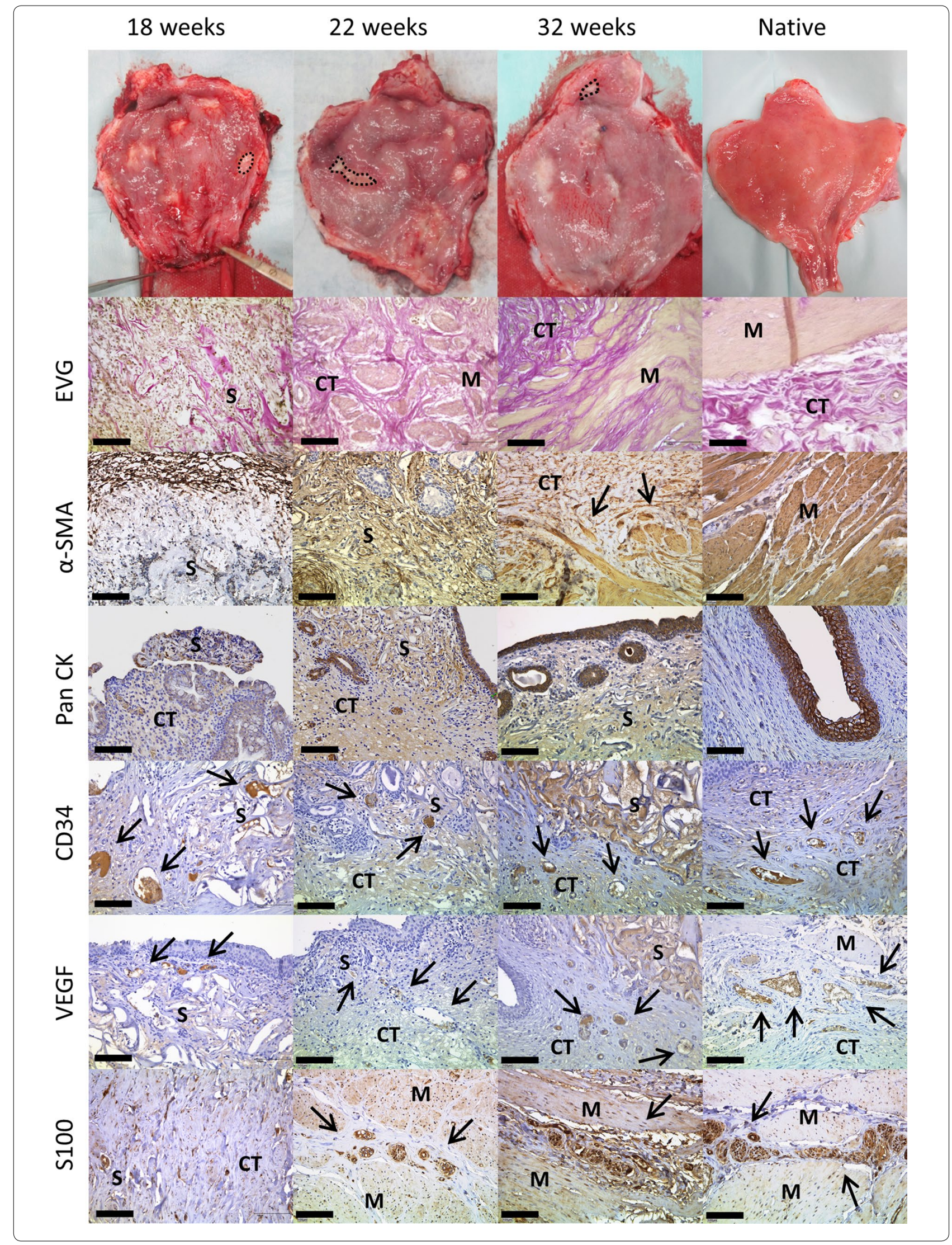


(See figure on previous page.)

Fig. 10 Histological development of implanted seeded OptiMaix 3D scaffolds. Similar to the unseeded OptiMaix 3D, the degradation has started after 6 weeks, but large pieces of the scaffold can still be found. At 18 weeks, parts of the scaffold structure are encapsulated by fibrotic tissue (a-SMA), which might be due to the protein component of the cell culture medium. This phenomenon cannot be found at later time points. As in the unseeded scaffolds, the urothelium is closed at 18 weeks and gradually building a smooth layer like in the native tissue. Overall, no differences can be found between the building of a new urothelial lining (PanCK), the degradation of the scaffolds (EVG), blood vessels (CD34, VEGF) or nerve fibre ingrowth (S100) compared to the unseeded scaffold. S scaffold, M muscle, CT connective tissue. Scale bar $=50 \mu \mathrm{m}$

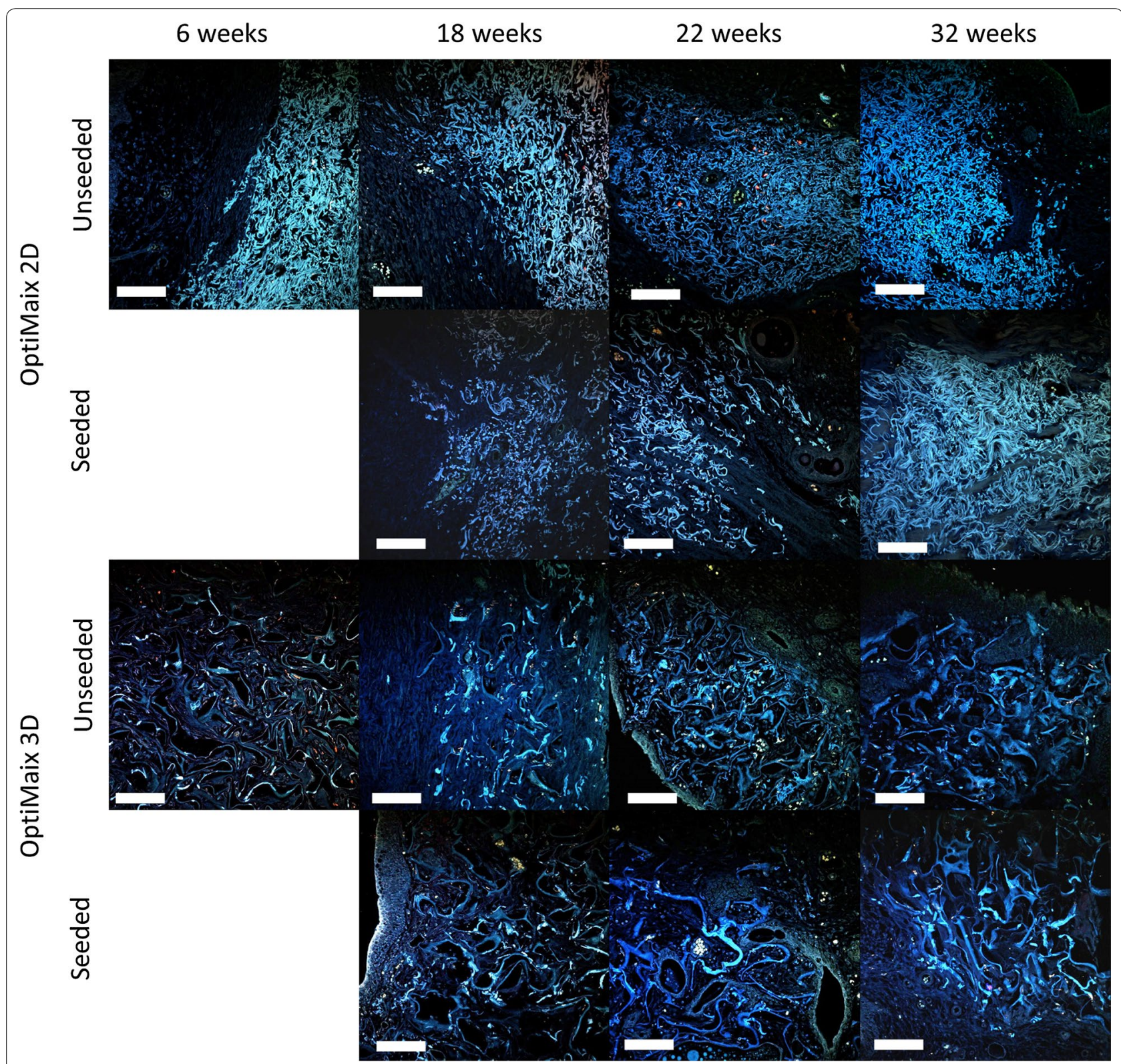

Fig. 11 TPLSM - autofluorescence of unseeded (above) and seeded (below) OptiMaix scaffolds. After 6 weeks, 2D still appears compact but is degrading and infiltrated by the adjacent bladder tissue. The 3D scaffold enhances the ingrowth of connective and muscle tissue due to its spongelike structure. After 32 weeks, large pieces of both OptiMaix scaffold types are still detectable in the peripheral regions on the luminal side of the implantation sites. Scale bar $=100 \mu \mathrm{m}$ 
between the micturition volumes before and after the operations, these were not significant and at the end point of the experiment all animals had regained normal bladder function. Furthermore, we had no indications for reflux, incontinence or graft failure which are common problems in urinary tissue engineering studies $[19,38]$.

The flexibility of the OptiMaix 3D allowed a temporary dilatation of the bladder wall before the recovery process had started and the ingrowing tissue stabilized the implantation sites. As this is the first time that these scaffolds are tested in vivo for urinary bladder augmentation, this is a critical outcome.

We did not find any significant indications that seeding with autologous bladder cells had improved ingrowth into the bladder wall. Here, the small size of the scaffolds together with the sealing with serosa might have promoted the ingrowth of urothelium and detrusor muscle from the adjacent tissue resulting in a greater impact on the outcome than the seeding with cells. Additionally, the seeded 3D scaffolds, contrary to the unseeded, were encapsulated by fibrotic tissue at 6 weeks. This might be due to the fact that the cell-scaffold hybrids were incubated in cell culture medium containing FCS. The seeded 2D scaffolds did not show any signs of encapsulation which might be due to the smaller overall surface that also reduces the possibility for foreign proteins to adhere [39]. Also, the degradation of both scaffolds was not accelerated when seeded with autologous cells.

The vascularization process seemed elevated for the OptiMaix 2D scaffolds compared to 3D. Already after 6 weeks, first blood vessels had formed within the compact material. No inflammation response regarding the scaffolds occurred, which permits the conclusion of a good biocompatibility in vivo. This is further supported by the absence of stone- or biofilm-formation. Overall, the bladder function after the implantation was physiologic and even as $25 \%$ of the bladders are augmented. Not to mention, the bladder is withstanding the pressure and the scaffold implants whatsoever, are participating in the bladder function.

By TPLSM, it was clearly visible that after six weeks the OptiMaix 3D was much more fragmented compared to the $2 \mathrm{D}$. The degradation process, for both scaffolds, was not completed at 26 weeks. Especially in the fringe of the implantation site, remnants of the scaffolds could be detected, notably beneath the urothelium.

We are very well aware of the limitations of our study. A future approach should entail a partial cystectomy and therefore, the fabrication of a larger prototype is definitely necessary. Also, as we were already proposing in our in vitro study [37], a combination of both scaffolds could be advantageous and provide a more convenient support for both cell types in vitro and in vivo and lead to a more stable implantation site.
In this study, we only used healthy pigs and therefore cannot make a statement about the ingrowth of the material into morbid tissue. Similarly, the behaviour of urothelial cells isolated from a diseased bladder is impaired, which has to be taken into consideration $[6,40]$. The next logical step would be the use of animals with a diseased bladder, e.g. idiopathic detrusor over activity or bladder exstrophy $[19,41,42]$.

\section{Conclusions}

With this study, we were able to show that the OptiMaix scaffolds are very promising for bladder wall augmentation. On the one hand, OptiMaix 2D seems more favourable compared to its 3D counterpart regarding handling, easier implantation, a quicker tightness of the bladder, and better reaction of the surrounding tissue. On the other hand, the ingrowth of cells and tissue into the $3 \mathrm{D}$ is facilitated and a combination of both scaffold types could be promising. Nevertheless, the usage for bigger defects might include the necessity for seeding with cells, which has to be evaluated in future studies.

\section{Abbreviations \\ a-SMA: a-smooth muscle actin; BAMG: bladder acellular matrix graft; CD34: cluster of differentiation 34; DAPI: 4',6-Diamidin-2-phenylindol; EVG: Elastica van Giesson; FCS: fetal calf serum; HE: haematoxylin-eosin; IKVAV: isoleucine- lysine-valine-alanine-valine; MEM: modified Eagle's medium; OPI: opera- tion I; OPII: operation II; PanCK: pancytokeratin; PCL: polycaprolactone; PGA: polyglycolic acid; PLA: polylactic acid; RG: nuclear fast red-fast green; RGD: arginine-glycine-aspartic acid; SIS: small intestinal submucosa; SMC: smooth muscle cell; SPF: specific pathogen free; TPLSM: two photon laser scanning microscopy; UC: urothelial cells; VEGF: vascular endothelial growth factor.}

\section{Authors' contributions}

DL did the histological procession and evaluation and all analysis and statistical evaluation of the data and writing of the manuscript. DL, KS and VS assisted during the operations, cystography and ultrasound. DL and KS performed the cell culture experiments. VS developed the seeding ring. VS and JG designed the study. IMZ and JG performed the operations, cystography and ultrasound. MV performed TPLSM analyses. PKS revised the manuscript. RHT and JOG supervised the study, analysed the data and revised the manuscript. All authors read and approved the final manuscript.

\section{Author details}

1 Department of Urology, RWTH Aachen University Hospital, Pauwelsstraße 30, 52074 Aachen, Germany. ${ }^{2}$ FB 9 Department of Biomedical Engineering, Laboratory of Medical and Molecular Biology, Aachen University of Applied Sciences, Jülich, Germany. ${ }^{3}$ Interdisciplinary Center for Clinical Research IZKF Aachen, RWTH Aachen University Hospital, Aachen, Germany. ${ }^{4}$ Institute for Laboratory Animal Science and Experimental Surgery, RWTH Aachen University Hospital, Aachen, Germany.

\section{Acknowledgements}

We thank the research group of the Department of Urology especially Lydia Zimmermanns for technical support and the Institute of Laboratory Animal Sciences: Anna Woitok, DVM, Karl Heinz Riemek, and Thaddäus Stopinski for excellent animal care. This work was also supported by the Core Facility- "TwoPhoton Imaging", Interdisciplinary Centre for Clinical Research (IZKF), Faculty of Medicine at RWTH Aachen University.

Competing interests

The authors declare that they have no competing interests. 


\section{Availability of data and materials}

The datasets analysed in this study are available from the corresponding author on reasonable request.

\section{Ethics approval}

All experimental procedures were in accordance to the German legislation governing animal studies and the Guide for the Care and Use of Laboratory Animals (National Institutes of Health (NIH), Publication No 85-23, revised 2011). The study was approved and granted by the governmental Animal Care and Use Office (Landesamt für Natur Umwelt und Verbraucherschutz Nordrhein-Westfalen, Recklinghausen, Germany, AZ: 87-51.04.2010.A229).

\section{Funding}

The study was financially supported by an unrestricted educational grant from the Dr. R. Pfleger Foundation, Bamberg, Germany.

Received: 8 November 2016 Accepted: 18 December 2016 Published online: 04 January 2017

\section{References}

1. Yoo JJ, Meng J, Oberpenning F, Atala A. Bladder augmentation using allogenic bladder submucosa seeded with cells. Urology. 1998;51:221-5.

2. Reddy PP, Barrieras DJ, Wilson G, Bagli DJ, McLorie GA, Khoury AE, et al. Regeneration of functional bladder substitutes using large segment acellular matrix allografts in a porcine model. J Urol. 2000;164:936-41.

3. Bolland F, Southgate J. Bio-engineering urothelial cells for bladder tissue transplant. Expert Opin Biol Ther. 2008;8:1039-49.

4. Caione P, Boldrini R, Salerno A, Nappo SG. Bladder augmentation using acellular collagen biomatrix: a pilot experience in exstrophic patients. Pediatr Surg Int. 2012;28:421-8.

5. Garthwaite M, Hinley J, Cross W, Warwick RM, Ambrose A, Hardaker $\mathrm{H}$, et al. Use of donor bladder tissues for in vitro research. BJU Int. 2014:113:160-6.

6. Renninger M, Amend B, Seibold J, Feil G, Stenzl A, Sievert KD. Regeneration of the lower urinary tract. Clinical applications and future outlook. In: Gorodetsky R, Schafer R, editors. Stem cell-based tissue repair. Cambridge: The Royal Society of Chemistry; 2011. p. 324-45.

7. Atala A, Bauer SB, Soker S, Yoo JJ, Retik AB. Tissue-engineered autologous bladders for patients needing cystoplasty. Lancet. 2006;367:1241-6.

8. Apodaca G, Balestreire E, Birder LA. The uroepithelial-associated sensory web. Kidney Int. 2007;72:1057-64.

9. Birder L, Andersson K-E. Urothelial signaling. Physiol Rev. 2013;93:653-80.

10. Zarghooni S, Wunsch J, Bodenbenner M, Brueggmann D, Grando SA, Schwantes $U$, et al. Expression of muscarinic and nicotinic acetylcholine receptors in the mouse urothelium. Life Sci. 2007;80:2308-13.

11. Biers SM, Venn SN, Greenwell TJ. The past, present and future of augmentation cystoplasty. BJU Int. 2012;109:1280-93.

12. Atala A. Bioengineered tissues for urogenital, repair in children. Pediatr Res. 2008;63:569-75.

13. Yokoyama T, Huard J, Chancellor MB. Myoblast therapy for stress urinary incontinence and bladder dysfunction. World J Urol. 2000;18:56-61.

14. Desgrandchamps F. Biomaterials in functional reconstruction. Curr Opin Urol. 2000;10:201-6.

15. Ribeiro-Filho LA, Sievert K-D. Acellular matrix in urethral reconstruction. Adv Drug Deliv Rev. 2015;82-83:38-46.

16. Sloff $M$, Simaioforidis $V$, de Vries R, Oosterwijk E, Feitz W. Tissue engineering of the bladder-reality or myth? a systematic review. J Urol. 2014;192:1035-42.

17. Davis N, Mc Guire B, Callanan A, Flood H, Mc Gloughlin T. Xenogenic extracellular matrices as potential biomaterials for interposition grafting in urological surgery. J Urol. 2010;184:2246-53.

18. Feil G, Christ-Adler M, Maurer S, Corvin S, Rennekampff H-O, Krug J, et al. Investigations of urothelial cells seeded on commercially available small intestine submucosa. Eur Urol. 2006:50:1330-7.

19. Lin H-K, Madihally SV, Palmer B, Frimberger D, Fung K-M, Kropp BP. Biomatrices for bladder reconstruction. Adv Drug Deliv Rev. 2015;82-83:47-63.

20. Evren S, Loai Y, Antoon R, Islam S, Yeger H, Moore K, et al. Urinary bladder tissue engineering using natural scaffolds in a porcine model: role of toll-like receptors and impact of biomimetic molecules. Cell Tissues Organs. 2010;192:250-61.

21. Feil G, Daum L, Amend B, Maurer S, Renninger M, Vaegler M, et al. From tissue engineering to regenerative medicine in urology-the potential and the pitfalls. Adv Drug Deliv Rev. 2011;63:375-8.

22. Harrington DA, Cheng EY, Guler MO, Lee LK, Donovan JL, Claussen RC, et al. Branched peptide-amphiphiles as self-assembling coatings for tissue engineering scaffolds. J Biomed Mater Res A. 2006;78A:157-67.

23. Yao C, Hedrick M, Pareek G, Renzulli J, Haleblian G, Webster TJ. Nanostructured polyurethane-poly-lactic-co-glycolic acid scaffolds increase bladder tissue regeneration: an in vivo study. Int J Nanomed. 2013;8:3285-96.

24. Yu D-S, Lee CF, Chen HI, Chang SY. Bladder wall grafting in rats using saltmodified and collagen-coated polycaprolactone scaffolds: preliminary report. Int J Urol. 2007;14:939-44.

25. Brauers A, Jung PK, Thissen H, Pfannschmidt O, Michaeli W, Hoecker H, et al. Biocompatibility, cell adhesion, and degradation of surface-modified biodegradable polymers designed for the upper urinary tract. Tech Urol. 1998:4:214-20.

26. Jurgens WJ, Kroeze RJ, Bank RA, Ritt MJPF, Helder MN. Rapid attachment of adipose stromal cells on resorbable polymeric scaffolds facilitates the one-step surgical procedure for cartilage and bone tissue engineering purposes. J Orthop Res. 2011;29:853-60.

27. Bozkurt A, Brook GA, Moellers S, Lassner F, Sellhaus B, Weis J, et al. In vitro assessment of axonal growth using dorsal root ganglia explants in a novel three-dimensional collagen matrix. Tissue Eng. 2007;13:2971-9.

28. Fuehrmann T, Hillen LM, Montzka K, Woeltje M, Brook GA. Cell-Cell interactions of human neural progenitor-derived astrocytes within a microstructured 3D-scaffold. Biomaterials. 2010;31:7705-15.

29. Krenning G, Moonen JR, van Luyn MJA, Harmsen MC. Vascular smooth muscle cells for use in vascular tissue engineering obtained by endothelial-to-mesenchymal transdifferentiation (EnMT) on collagen matrices. Biomaterials. 2008;29:3703-11.

30. Kroehne V, Heschel I, Schuegner F, Lasrich D, Bartsch JW, Jockusch $\mathrm{H}$. Use of a novel collagen matrix with oriented pore structure for muscle cell differentiation in cell culture and in grafts. J Cell Mol Med. 2008;12:1640-8.

31. Saxena AK, Faraj KA, Damen WF, van Kuppevelt TH, Weijnen R, Ainoedhofer $\mathrm{H}$, et al. Comparison of collagen scaffold tubes for possible esophagus organ tissue engineering applications: in-situ omental implantation study in an ovine model. Eur Surg. 2010:42:309-13.

32. Montzka K, Laeufer T, Becker C, Grosse J, Heidenreich A. Microstructure and cytocompatibility of collagen matrices for urological tissue engineering. BJU Int. 2011;107:1974-81.

33. Brehmer B, Rohrmann D, Rau G, Jakse G. Bladder wall replacement by tissue engineering and autologous keratinocytes in minipigs. BJU Int. 2006;97:829-36.

34. Brehmer B, Rohrmann D, Becker C, Rau G, Jakse G. Different types of scaffolds for reconstruction of the urinary tract by tissue engineering. Urol Int. 2007:78:23-9.

35. Huppertz ND, Tolba RH, Grosse JO. Micturition in Gottingen minipigs. first reference invivo data for urological research and review of literature. Lab Anim. 2015:49:336-44.

36. Huppertz ND, Kirschner-Hermanns R, Tolba RH, Grosse JO. Telemetric monitoring of bladder function in female Gottingen minipigs. BJU Int. 2015;116:823-32.

37. Leonhäuser D, Vogt M, Tolba RH, Grosse JO. Potential in two types of collagen scaffolds for urological tissue engineering applications-are there differrences in growth behaviour of juvenile and adult vesical cells? J Biomater Appl. 2016;30(961-973):38.

38. Song L, Murphy SV, Yang B, Xu Y, Zhang Y, Atala A. Bladder acellular matrix and its application in bladder augmentation. Tissue Eng Part B. 2014;20:163-72.

39. Anderson JM, Rodriguez A, Chang DT. Foreign body reaction to biomaterials. Semin Immunol. 2008;20:86-100.

40. Lin HK, Cowan R, Moore P, Zhang YY, Yang Q, Peterson JA, et al. Characterization of neuropathic bladder smooth muscle cells in culture. J Urol. 2004;171:1348-52.

41. Akbal C, Lee SD, Packer SC, Davis MM, Rink RC, Kaefer M. Bladder augmentation with acellular dermal biomatrix in a diseased animal model. J Urol. 2006:176:1706-11.

42. Roelofs LAJ, Kortmann BBM, Oosterwijk E, Eggink AJ, Tiemessen DM, Crevels AJ, et al. Tissue engineering of diseased bladder using a collagen scaffold in a bladder exstrophy model. BJU Int. 2014;114:447-57. 